\title{
Navigating the occupational transition of dropping out of school: Anchoring occupations and champions as facilitators
}

\author{
Liesl Peters, BSc OT (UCT), MSc OT (UCT) \\ Lecturer, Division of Occupational Therapy, Department of Health \& Rehabilitation Sciences, University of Cape Town
}

Roshan Galvaan, BSc OT (UCT), MSc OT (UCT), PhD (UCT)

Associate Professor and Head of Division of Occupational Therapy, Division of Occupational Therapy, Department of Health \& Rehabilitation Sciences, University of Cape Town

\section{Harsha Kathard, B Speech and Hearing Therapy (UDW), M Speech Pathology (UDW), Doctor of Education (UDW)}

Professor: Communication Sciences and Disorders, Interim Head: Department of Health Sciences Education, University of Cape Town

This paper has the dual aim of first presenting an understanding of school dropout as an occupational transition and second, to suggest how this occupational transition may be navigated successfully. School dropout is of concern to occupational therapy as it limits peoples' full social inclusion. We draw on data from a biographical inquiry into the nature of occupational engagement of men in a low socioeconomic, South African community who dropped out of school. In this study, narrative data were generated from 3 men, followed by a narrative analysis and thematic analysis. The findings reflected that two of the men established stable occupational trajectories after dropping out of school, contrasted with the third man who was unable to do this. The interpretations suggest that a successful occupational transition for these two participants occurred through establishing anchoring occupations as a result of chance encounters with individuals who acted as 'champions'. These champions ensured the successful negotiation of available opportunities. Through offering these insights, this paper provides an illustration of how concepts interpreted and discussed in occupational science, such as occupational transitions, have relevance to occupational therapy. With regards to the occupational transition of dropping out of school, it is recommended that occupational therapists consider how they might promote access to champions of opportunities that lead to the development of anchoring occupations.

Key words: occupational transition, school dropout, anchoring occupations, champions

\section{INTRODUCTION}

School dropout is recognised as a problem world-wide, but is particularly prevalent in countries where poverty and inequality prevails'. South Africa demonstrates particularly poor educational attainment for the majority of its citizens ${ }^{2}$. The $201 \mathrm{I}$ census data showed that $4,6 \%$ of the South African population who were 20 years or older at the time of the census had completed primary school and of these individuals only $28,9 \%$ had completed high school ${ }^{3}$. This is reflective of South Africa's history in that black people ${ }^{a}$, living in communities with a low socio-economic status have access to a lower quality education ${ }^{4}$. When comparing dropout across different age bands the situation is marginally better for younger individuals in South Africa ${ }^{3}$, given the advent of South Africa's democracy in 1994. However, the 2014 General Household Survey suggests that there is still a sharp decline in educational participation in the country for those 15 years and older ${ }^{5}$.

The consequences of dropping out of school are multiple, the most prominent being that youth leave school without acquiring sufficient skills and credentials, potentially curtailing their access to the labour market ${ }^{2}$. Although educational attainment influences successful access to work $^{2}$, there are no studies that focus on school dropout in the occupational therapy or occupational science literature. Since social inclusion is mediated through participation in the occupations

a In this paper the term 'black people' is inclusive of people who under Apartheid rule were designated as African black, coloured and Indian of daily life ${ }^{6}$ occupational therapists should be concerned about how people who drop out of school are able to participate in society.

\begin{abstract}
Literature Review
The first part of this review indicates that school dropout can be understood as an occupational transition given its features as a particular transition in the life course. The sections that follow, review the literature on school dropout from various disciplines by relating it back to the various facets of school dropout as an occupational transition.
\end{abstract}

\section{Conceptualising school dropout as an occupational transition}

Studies on school dropout in other disciplines provide some understanding of this phenomenon, however they call for studies to explore this in new ways ${ }^{7}$. While previous studies describe the factors contributing to or mitigating against school dropout, a longitudinal perspective of this phenomenon that provides an understanding of how people who drop out of school structure their occupational trajectories, is missing. An occupational perspective offers new understanding when focusing on the relationship between giving up a major occupation (i.e. school leaving) in favour of other endeavours. When dropping out of school, learners go through a transition during which a major occupation is lost (schooling), to be replaced by different occupational pursuits. This is consistent with the Occupational Science definition of an 
occupational transition as "a major change in the occupational repertoire of a person in which one or several occupations change, disappear and/or are replaced by others" $8: 212$.

Occupational transition is a recently developed concept that explains how people negotiate life changes. The literature on occupational transitions reveals that, with respect to major changes to individuals' occupational repertoires, authors have discussed transitions of homelessness and addiction ${ }^{9}$, forced migration ${ }^{10}$, immigration ${ }^{11,12}$, driving cessation ${ }^{13}$ and retirement ${ }^{8,14-17}$. A review of these studies indicated that:

* Continuity with previous patterns of occupational engagement may be sought subsequent to the transition ${ }^{17}$.

* The alteration of occupational patterns subsequent to the transition may be of significance and context could influence how new patterns emerge $e^{8,15,16}$.

$*$ The disruption of usual occupational patterns is a significant aspect in the development of the new occupational repertoire ${ }^{13}$.

* Occupations with certain kinds of characteristics play a role in the successful negotiation of occupational transitions ${ }^{8,15}$. Another study on the centrality of occupation during life transitions indicated that the nature of occupational engagement at the point of the transition might be important in determining the successful negotiation of the transition ${ }^{18}$.

The next sections review studies on school dropout from other disciplines in relation to the insights into the concept of an occupational transition described above.

Insights about the patterns of occupational engagement of school dropouts ${ }^{\mathrm{b}}$ prior to the occupational transition Prior to dropping out, most school dropouts slowly became disengaged from school, began playing truant and engaging in drug abuse ${ }^{|9-2|}$. In South Africa, peer pressure was one of the reasons that school dropouts engaged in these ways ${ }^{21}$. Another study conducted within two South African educational districts found that poor school performance precipitated the decision to leave school $^{22}$. Occupational engagement characterised by poor academic performance and participation in risky occupations was a significant aspect of school dropouts' participation prior to dropping out and their eventual reason for dropout in other studies too ${ }^{23,24}$.

Mahoney and Cairns ${ }^{25}$ and Ream and Rumberger ${ }^{26}$ found that school dropouts consistently participated in fewer extra-mural activities prior to dropping out when compared with their peers who stayed in school. This suggests that school dropouts are not involved or may not have access to occupations that might protect them against dropping out ${ }^{26}$. These individuals approach the occupational transition of dropping out with the limited participation in extramural occupations that may enrich their lives ${ }^{27}$. Poor school-related participation is indicative of participation prior to dropping out ${ }^{26}$ that both contributes to the transition occurring and also does not assist once the transition has occurred. We caution against viewing this as stereotyping the school dropout, but rather to recognise that there are limitations in education systems that disadvantage individuals ${ }^{7}$.

Insights about occupational engagement after the occupational transition

Floundering after dropping out is common and attributed to the school dropouts' developmental stage and the factors which cause dropout $^{28,29}$. Similar to international comparisons ${ }^{7}$ the South African school dropouts' occupational engagement tends to be restricted, with dropouts comparing it to "living in a prison"21:2. Their difficulty with finding sustainable employment left dropouts "sit(ting) at home.......do(ing) nothing"21:7. This suggests that participation in school is not easily replaced by other occupations $\mathbf{s}^{30,2}$. An earlier

b The term school dropouts is used in this paper as opposed to 'people who drop out of school' to facilitate ease of reading. It is by no means meant to be derogatory and demeaning. quantitative study in the USA and Australia compared the in and out of school activities of youth and found that school dropouts' participation in occupations after dropping out reflected the opportunities available in their immediate contexts ${ }^{31}$. The pattern of engagement in risky occupations post dropping out was echoed in a number of studies ${ }^{31-34}$. The places where school dropouts spend their time after dropping out, such as the street corners in low socio-economic communities, induce them into risk occupations, such as drinking, drug abuse and participation in illegal activities ${ }^{2 !}$.

Successfully negotiating the occupational transition of dropping out of school: A missing perspective

The literature on school dropout from other disciplines illustrates the vulnerable position of school dropouts and focusses on the activities that led to them dropping out of school as well as some of the high risk activities that they may continue to participate in after leaving school. The studies reviewed do not suggest which kinds of occupations replace that of school or that school is necessarily immediately replaced by other kinds of occupation. There were thus similarities between this occupational transition and others $s^{8,15,16}$. Resources available in the context appear to significantly influence the kinds of occupational repertoires that can emerge for school dropouts ${ }^{21}$. This was also evident when considering the previous studies done on the occupational transition of retirement ${ }^{8,14-17}$.

The studies presented in this review show that the kind of occupational engagement leading up to dropout and afterwards is characterised by risk. However, descriptions of how school dropouts' full occupational trajectories are constructed after navigating this occupational transition are unclear. Whether these individuals continue to seek continuity with previous engagement, or find new ways of participating in occupations as they negotiate this occupational transition, was not evident from previous research done. For occupational therapists, the lack of such knowledge compromises our understanding of how the occupational transition of school dropout may be negotiated, and how the building of subsequent occupational trajectories might be facilitated. Viewing school dropout as an occupational transition is a helpful starting point for beginning to consider the issues that school dropouts might face in constructing stable occupational trajectories. This paper goes further to offer suggestions for how the occupational transition of school dropout might be negotiated successfully by drawing on a particular aspect of the findings of a biographical study, which is described in the next section.

\section{METHOD}

The first author initiated a study $(2009-201 \mathrm{I})$ to describe the nature of the occupational engagement of men in Lavender Hill who had dropped out of school. Her experience as an occupational therapist working with young adolescents in Lavender Hill, a low socio-economic community in Cape Town, compelled her to explore what happened to young adolescents after they dropped out. The first author's experience suggested that women often leave school to take up child-rearing and household responsibilities, while men leave for other reasons. This has been shown to be the case in the broader South African population ${ }^{5}$. Men's occupational trajectories could possibly be influenced differently given their reason for leaving school and the kinds of occupations available to them on leaving. The study therefore asked: What is the nature of the occupational engagement of men who have dropped out of school and who live in Lavender Hill?

\section{Design}

A qualitative biographical study design was selected because of its value in understanding phenomena from a longitudinal perspective. Biographies are one of the best data generation methods for understanding occupation over the life course ${ }^{35}$. An interpretive approach was applied ${ }^{36}$ prioritising a process during which the researcher and participants co-constructed the data that were 
generated and analysed. This included paying attention to the way that data generation occurred during the interview process ${ }^{37}$ and consistently checking the interpretations made with participants ${ }^{38}$. The result of this process was an interpretation of the study findings representing the different perspectives of the first author and the participants.

\section{Selection of participants}

Purposive sampling was used to select participants. Key informants, who were well known in Lavender Hill and with whom the first author had developed working relationships assisted with identifying potential participants. The selection criteria included that all participants needed to:

\section{* Be men}

$\rightarrow$ Be 20 years or older at the time of the study. The chronological age of potential participants at the time of the study was important as the participants needed to have had time for their life trajectories to unfold.

* Have been living in Lavender Hill prior to or since dropping out of school.

* Have no evident cognitive impairment that would prevent the recounting of their life story.

The selection of participants occurred progressively over five months. As each new participant's story emerged, the selection of the next participant encompassed how a different perspective of emerging phenomena could be explored. Furthermore, variations including the age of participants at the time that they dropped out, the age and employment status of participants at the time of the study, and their employment histories influenced selection. The biographical profile of the three participants is presented below. Pseudonyms are applied throughout this paper to protect the confidentiality of participants and other people about whom each shared during the research interviews.

Table I: Biographical profile of participants

\begin{tabular}{|l|l|l|l|l|}
\hline Participant & $\begin{array}{l}\text { Age } \\
\text { (at time of } \\
\text { initiating } \\
\text { data } \\
\text { generation) }\end{array}$ & $\begin{array}{l}\text { Grade/ } \\
\text { age when } \\
\text { participant } \\
\text { decided } \\
\text { to leave } \\
\text { school }\end{array}$ & $\begin{array}{l}\text { Highest } \\
\text { grade } \\
\text { attained }\end{array}$ & $\begin{array}{l}\text { Current work } \\
\text { occupation and level } \\
\text { of success }\end{array}$ \\
\hline Clino & 29 years & Grade II & Grade 10 & $\begin{array}{l}\text { Unemployed at the } \\
\text { time of the study; was } \\
\text { periodically engaged in } \\
\text { contract work. }\end{array}$ \\
\hline Gavin & 49 years & Grade 6 & Grade 6 & $\begin{array}{l}\text { Pastor; deeply } \\
\text { respected within the } \\
\text { community. }\end{array}$ \\
\hline Ralphi & 38 years & Grade 10 & Grade 9 & $\begin{array}{l}\text { Grounds man; } \\
\text { respected for his } \\
\text { contribution at the } \\
\text { school at which he } \\
\text { worked. }\end{array}$ \\
\hline
\end{tabular}

\section{Data generation}

Through a series of three in-depth interviews with each participant, topical life stories ${ }^{37}$ were generated as data. During each I - 2 hour long interview, a set of objective events relating to the way that the South African schooling system was constituted and the developmental stages across the lifespan brought structure to the men's recounting of their stories ${ }^{37}$. This enabled them to engage in free story telling whilst situating their experiences within a chronological time frame ${ }^{36}$. Following Atkinson's methods ${ }^{39}$, the initial interview asked "Where would you like to begin in telling me your story?" This sufficiently broad question encouraged a full story to emerge and was followed up by specific questions for each participant.

\section{Data analysis and interpretation}

Data analysis followed an iterative process. A narrative analysis ${ }^{40}$ yielding research stories was followed by a second level thematic analysis ${ }^{41,42}$. The thematic analysis sharpened elements of the research stories, strengthening the narrative analysis. Acknowledging that an interpretive approach offers only one possible interpretation of the data, it is plausible that other interpretations could be constructed. However, the research story together with the embedded interpretations were checked, in a further hour-long session with each participant. One participant took the opportunity to extend his story by adding further developments and in so doing enhanced the depth and coherence of the interpretations. Although it is acknowledged that the data were co-constructed ${ }^{37}$ the first author privileged participants' perspectives over her own, given her different social position. Offering an interpretation of school dropout in this study was a starting point, coherent with the purpose of biographical research, which is to propose possible initial interpretations that can be taken further in future research ${ }^{37}$.

\section{Trustworthiness and Ethics}

Interpretive biographical research has its own set of standards for establishing the trustworthiness of the research findings ${ }^{38}$. Applying Riessman ${ }^{38}$ and Blumenfeld-Jones' ${ }^{43}$ guidelines in this study involved tracking the internal consistency of the participants' accounts, which included evaluating whether there was consistency in different parts of the story; using the principle of persuasion and plausibility as a measure of believability; and using the principle of correspondence as a form of member checking. Corresponding with each participant regarding the veracity of the research stories confirmed that these were indeed accurate accounts. Traditional approaches for establishing trustworthiness were also incorporated and included keeping a reflexive journal, peer debriefing and using an audit trail ${ }^{44}$.

This study received approval from the University of Cape Town, Faculty of Health Sciences Human Research Ethics Committee. Full informed consent was obtained from each participant. Anonimity was maintained in a careful manner since people become easily identifiable when presenting their life story ${ }^{37}$. This involved altering details that did not change the truthfulness of the data but that would protect each participant's identity when sharing the findings.

\section{FINDINGS}

The biographical method requires that data are presented and read as a coherent whole, since many of the insights arise as a result of interrogating the full story $^{36}$. However, this paper selects only the poignant aspects of the data to make an argument regarding the successful negotiation of school dropout. We used both direct quotations from the analysis of narratives and excerpts from the narrative analysis to illustrate our argument.

The cross-case analysis of the research stories offered an important perspective since, against all expectations, two of the three participants managed to establish stable life trajectories, which contributed to the negotiation of this occupational transition. In this section we provide a brief presentation of the theme followed by an explanation of only the first two categories that emerged in the full study. It is thought that these categories give voice to the factors influencing the successful negotiation of this occupational transition. The perspectives presented here were considered in relation to each participant's full life story and have not been taken out of context.

\section{Theme - Lots of uncertainty and some power}

The theme described the way that the highly precarious nature of the participants' occupational engagement came to be, since changes in occupational engagement were dependent on chance. Chance was defined as a lucky and co-incidental encounter or 
opportunity for occupational engagement, which was beyond the control of the participants. In fact, participants displayed preserved patterns of participation that were consistent with their occupational engagement prior to dropping out of school (category I) and that reflected the dominant ideologies in their context. Their situations only changed when acted on by an external influence (category 2). Anchoring occupations, a particular kind of occupation that emerged for two of the participants, contributed to the power that each experienced in being able to mediate the extent of the uncertainty of their occupational engagement within the context of their life trajectories.

\section{Category I - Preserved patterns of participation: "Niks} gechange nie" (Nothing Changes)

Preserved patterns of participation emerged as those occupations that the participants possessed at the point of transition and performed consistently over time. The patterns also reflected the consistent way in which participants chose to act within their occupations. The men's patterns of participation revealed that initially nothing changed since they showed similar patterns of occupational engagement just prior to and after dropping out of school, reflecting reckless patterns of occupational engagement.

At night, Elroy used to ask his mom for the key to the bungalow so we could shoot some pool. Some of the nights, we used to break the pool table to steal the money, and then buy a klomp [bunch of] beers and drink there 'til the morning with some girls. That was what my life was like during that time. I knew exactly what my plan was for each day, net drink, elke dag [just drinking, every day]! The only work I could find when I left school was building work like carpentry, bricklaying and painting. There were so many different jobs in the beginning... ...I didn't really stay long at any of the jobs - some for two days, some three..

Clino

Where new occupations were taken on this often occurred in a haphazard manner. Piecemeal employment was the norm with participants entering and leaving work often. This is reflected in the following excerpts from Gavin and Ralphi's stories:

. I started to do naughty things. I smoked. I drank. I did the things that the older men at the garage did...... I took the drinking and smoking with me to [my next job at] the factory. I worked at Bagmores for two years. When my aunt saw the way things were she tried to get me a job where she worked as a general cleaner. It didn't work out though and I found my next job as a plumber through my uncle. I lost that job during the riots in the 1980's and after that I found employment in another factory.

Gavin

Everyday was the same. I would wake up late. Watch soapies on TV. Drink a cup of tea. There's not much to do when you don't have anyone helping to give you structure. I was so frustrated with my situation... ... got my first job at the Simonstown Docks where I worked first as a painter and in the French Polishing section. After that I got a job as a painter at Popular Painters and after that with a hardware store, which closed down soon after. Then I worked at Bruce's Engineering.

Ralphi

The preserved patterns of participation were influenced strongly by what was expected of men living in Lavender Hill and the occupations available to participate in. Opportunities for introducing positive changes to these patterns are discussed in category 2 below.

Category 2 - Champions and anchoring occupations as provocateurs for change: “Dit kan beter wees” (It can be better)

This category illustrates how the participants' preserved patterns of participation could be intercepted by the presentation of chance opportunities for participation and a key individual - a champion - in their lives who would assist them to engage with these. Particular opportunities resulted in the development of anchoring occupations, which held a central place in participants' lives and appeared to stabilise their occupational trajectories.

The excerpt from each participant's research story below highlights the stark contrast when anchoring occupations were present (Ralphi and Gavin's stories) as compared to when they were not present (Clino's story). While preserved patterns of participation were initially central in defining the potential direction of the occupational trajectory for all participants, Gavin and Ralphi's stories indicate that anchoring occupations shifted this situation. When considering these excerpts the reader is invited to pay attention to the manner by which the opportunity to participate in the anchoring occupation came about, illustrating the role that particular individuals played in assisting Gavin and Ralphi to negotiate these.

\section{Ralphi: An opportunity presents itself}

I still remember the day when my eldest son came home and told me something that made me sit up and take notice. By a twist of fate, his teacher had asked whose daddy was at home and he had told her that I was at home without work. His teacher had asked him to ask me to come into the school because there was some part-time work available. The school needed someone to put some new windows in.

His teacher was Miss Fiela Adams.

She has been my guardian. Once I started working at Olivia Primary, doing odd jobs, Miss Adams always made sure that I had something. She negotiated with some contractors who were working at the school and I ended up doing some work for them, painting the school roof. In the meantime, Miss Adams was busy negotiating with the school for me to be put on contract. After four or five years of working on contract, I was made permanent. And l've kept this job. I've made something of myself. I am proud that I am able to do things for my community. I am on the school governing body and I'm good at it because I understand my community and how it works. People respect me here - even those parents at the school who are big gangsters greet me when I see them in the street. I can go anywhere in Lavender Hill and people treat me this way.

\section{Gavin: The opportunities multiplied}

Shortly after losing my job as a plumber, I found employment in another factory called Fellow Fabrics. I can say to this day, with complete certainty that my life would have been very different if I had never gone to work at Fellow Fabrics and met Johnnie Jillespie. Johnnie was the role model I had been looking for in a man. He encouraged me to try my life differently. To see things from a different perspective. A perspective that was God's perspective and not my own. Fate brought us together and I thank God for that...... With this personal change came a deepening of my commitment to everything in my life. At work, people started to notice me. Everyone liked me and I liked them. I had become something different. And so I started to climb the ladder to more important places in the factory. I worked at Bagmores for 23 years, until my life reached another fork in the road. This time the road was to 'somewhere'. First I became a Sunday School teacher. After a while, I took up the position of deacon, then elder, then head elder. I had never dreamt of high positions, or of going anywhere significant in my life. Yes, I had always wanted more, but I never thought I would get here! I was ordained as a pastor in 1995 but I was still working at Bagmores. Eventually I was called in by my boss at the factory and he told me that I couldn't go on like this. I had to make a choice. That choice wasn't difficult for me. I knew who I was and what I wanted from life. I chose the church. 
Clino: Resigned to second best

It's much more difficult to find work these days. I don't know if it has to do with the economy or what. Perhaps it's that I don't have the right qualifications. Things don't seem to be working out for me...... In the last year, I have started to work on computers with my brother-in-law and his friend. They have taught me to take computers apart and put them together again. I am doing okay with it, but those two are the ones that really know what they are doing. Sometimes, if they don't feel like doing something and they know I can do it, then they give the job to me. We don't have it going as a business yet, but I would really like it to grow. If I have my own business, I won't have anyone telling me to do this and that. I have thought about getting business cards to advertise, but we don't have the qualifications. Where must we get the papers from to say we can do this? I guess we must just be happy fixing 'back door' computers.

The stories indicate how Fiela Adams acted as a champion for Ralphi and Johnnie Jillespie for Gavin. We term these individuals champions because they looked for and created access to opportunities for participants and without them it is unlikely that participants would have developed anchoring occupations. There were instances evident in other parts of all three participants' research stories where there was potential to take hold of an opportunity for participation but this did not materialise for a variety of reasons. Champions enhanced participants' capability to navigate opportunities that were available to them and also looked to create new opportunities.

The combination of champions and resulting anchoring occupations appeared to be powerful in shifting occupational engagement and created opportunities for the men to realise different possibilities. Initial participation developed into prolonged engagement, which provided the opportunity for participants to realise a form of growth and development that contributed positively to their well being.

The continued participation in anchoring occupations shaped these particular participants' views and understanding of themselves positively, contributing to their sense of identity. This played a role in positively constructing and orienting their occupational identity at these points in their lives.

Gavin and Ralphi were able to experience a sense of purpose through their involvement in these anchoring occupations. Both participants understood their participation in these occupations as contributing to their community, giving them a sense of belonging. Their experience of this sense of belonging served to ground and extend their participation in their anchoring occupations. Having access to anchoring occupations influenced the participants' sense of satisfaction with their lives.

Ralphi: But I also, I am satisfied with where I am today. I don't think I am really short of anything in my life because the people that I work with, they make me feel at home.

This is contrasted with Clino's expression of his dissatisfaction:

.I am nearly 30 already and I haven't done anything with my life... .I am getting so frustrated...

\section{DISCUSSION}

This study suggests that school dropouts may experience continued participation in their potentially compromising patterns of occupational engagement after stopping school. This continuity of patterns is consistent with the idea proposed by Wiseman and Whiteford ${ }^{17}$ that people might seek such continuity when navigating occupational transitions. The findings of this study suggest that in the context of school dropout continuity is, however, not always desirable. This may be because the school dropout's occupational repertoire at the point of dropping out is still being established, given their age and stage of development. Further to this, the influence of low socio- economic contexts limited the school dropouts' occupational repertoires in this study, often due to their marginalised race and class positions. These young people did not have a good platform from which to build new occupational patterns after dropping out. This is significant because, although a sense of continuity is not desirable it may become the natural predisposition for school dropouts, since the limitations of the context cannot be easily overcome. School dropouts might also experience what Johnson termed the "paradox of freedom'8 in his study on retirement. Although freedom to do what they wished was the desire of the school dropouts, in reality they were left with the need to continue participating in occupations that they knew in order to make or keep life manageable. In a potential effort to structure their time in the absence of school they perpetuated previous patterns of participation.

Anchoring occupations served to disrupt this continuity in positive ways, forcing a renegotiation of occupational patterns that broke from the previous structure of participation. The characteristics of these occupations and the mechanisms by which they come about are important contributors to the way in which this disruption happens. The way anchoring occupations are constituted resonates strongly with theory of engaging occupations in retirement ${ }^{8}$.

Engaging occupations were found to have a number of positive elements that ensured they contributed to the successful negotiation of retirement ${ }^{8}$. These elements included that they were infused with positive meaning, were analogous to work and that they were intense, requiring regular engagement over a lengthy period of time ${ }^{8}$. Johnson, Josephsson and Kielhofner ${ }^{14}$ highlighted that engaging occupations 'sometimes reaffirmed a person's worth or identity. We can thus see that there are close parallels between these descriptions of engaging occupations and that of anchoring occupations in Gavin and Ralphi's life stories. What we can learn from this alignment is that people might require a central occupation around which to rebuild their lives following a significant occupational transition. In other words, any transition that results in a significant change in one or more occupations requires that the occupation that is lost be replaced with at least one other occupation that is viewed as personally significant for the individual concerned. The central character of the occupation becomes important when considering the point in the lifespan at which the occupational transition in question is experienced. Since school dropouts are on the brink of entering adulthood at the point of transition, occupations that are anchoring in nature are essential for their experience of health and well being. Since anchoring occupations and engaging occupations are so closely aligned, it is thought that an anchoring occupation may be a particular form of an engaging occupation.

\section{Anchoring occupations, chance and vulnerable groups}

Much of occupational therapy theory tends to originate from theorists in the North and frames the development of the occupational trajectory from this perspective ${ }^{45}$. This results in particular expectations and interpretations of what constitutes participation within and across phases of life. Observation of the social stratifications inherent in society reveals that dominant groups have taken-forgranted access to anchoring occupations. These anchoring occupations, whether they are work occupations or other occupations, are important because they provide stability in adulthood and focus the development of the life trajectory. Their presence is therefore rarely questioned in terms of their relative value and contribution. However, individuals who form part of marginalised social groups - such as school dropouts from Lavender Hill who do not automatically have access to anchoring occupations - would keenly feel this lack. This was powerfully illustrated in Clino's story. Insufficient attention to the establishment of anchoring occupations for vulnerable individuals experiencing school dropout may have consequences for their health and well being.

In our study the development of anchoring occupations was largely dependent on the lucky and coincidental presentation of an opportunity for occupational engagement through a champion. This 
is problematic because it means that the establishment of anchoring occupations, which is a direct opportunity for school dropouts to challenge the uncertain nature of their occupational engagement, is solely reliant on the whims of chance. The place of the champion, who ensured that the opportunities for participation were both seen and taken up, is significant for occupational therapy practice as it provides insights into how to enable access to anchoring occupations. Occupational therapists have a history of working with vulnerable youth and should consider the kinds of opportunities and champions that should be available to young people who drop out of school in order to provide a platform from which anchoring occupations can be developed. This might involve acting as, or devising ways of accessing, a 'champion' for these individuals and would mean that occupational therapists become attuned to the kinds of opportunities and support an individual requires to help them negotiate participation in anchoring occupations. This offers new ways of thinking about interventions that could enable more supportive environments.

\section{CONCLUSION}

This paper has positioned school dropout as an occupational transition with important lessons for the construction of a stable occupational trajectory after such a transition. The central place of an anchoring occupation and champion has been emphasised as a way of disrupting limiting patterns of participation following such a transition. Anchoring occupations have been shown to hold particular characteristics that allow for the positive situation of the occupational trajectory for school dropouts in challenging contexts. Particularly concerning is that anchoring occupations emerge largely as a result of chance, a facet that has not been considered in depth in occupational therapy practice.

Although occupational therapists have not traditionally worked with school dropouts as a group, this is an area of practice that should be considered given the complexity of this occupational transition. However, in varied areas of practice occupational therapists might discover that the individuals they work with dropped out of school and are therefore encouraged to engage further with research on anchoring occupations and the roles of champions with respect to school dropouts and other vulnerable groups.

\section{REFERENCES}

I. Sabates R, Akyeampong K, Westbrook J, Hunt F. School Drop out: Patterns, Causes, Changes and Policies. Background paper prepared for the Education for All Global Monitoring Report 20 I I: The hidden crisis: Armed conflict and education. United Nations Educational, Scientific and Cultural Organisation, $20 \mathrm{I} 0$.

2. Branson N, Garlick J, Lam D, Leibrandt M. Education and Inequality: The South African Case. Cape Town: South African Labour and Development Research Unit University of Cape Town, 2012.

3. Statistics South Africa. Census 201 I statistical release - P030I.4. Pretoria, South Africa, 2012.

4. Spaull N. Poverty and Privilege: Primary School Inequality in South Africa. International Journal of Educational Development. 20। 3; 33(5): 436-47.

5. Statistics South Africa. General Household Survey 2014. Pretoria: Statistics South Africa, 2015.

6. Whiteford G, Pereira R. Occupation, social inclusion and participation. In: Whiteford G, Hocking C, editors. Occupational Science: Society, Inclusion, Participation. London: Wiley-Blackwell, 2012.

7. De Witte K, Cabus S, Thyssen G, Groot W, van den Brink HM. A critical review of the literature on school dropout. Educational Research Review. 2013;10:13-28.

8. Jonsson $\mathrm{H}$. Occupational Transitions: Work to Retirement. In: Townsend L, Christiansen $\mathrm{CH}$, editors. Introduction to Occupation: The art and science of living. 2nd ed: Prentice Hall; 2010: 21 I-30.

9. Heuchemer B, Josephsson S. Leaving homelessness and addiction: Narratives of an occupational transition. Scandanavian Journal of Occupational Therapy. 2006;13:160-9.

10. Suleman A, Whiteford GE. Understanding Occupational Transitions in Forced Migration: The Importance of Life Skills in Early Refugee Resettlement. Journal of Occupational Science. 20I3; 20(2): $20 \mathrm{I}$ - I0.
II. Suto M. Compromised careers: The occupational transition of immigration and resettlement. Work. 2009; 32: 4I7-29.

12. Hon C, Sun P, Suto M, Forwell S. Moving from China to Canada: Occupational Transitions of Immigrant Mothers of Children with Special Needs. Journal of Occupational Science. 20 I ; 18(3): 223-36.

13. Vrkljan BH, Polgar JM. Linking occupational participation and occupational identity: An Exploratory Study of the Transition from Driving to Driving Cessation in Older Adulthood. Journal of Occupational Science. 2007; I4(I): 30-9.

14. Jonsson H, Josephsson S, Kielhofner G. Narratives and Experience in an Occupational Transition: A longitudinal Study of the Retirement Process. The American Journal of Occupational Therapy. 200 I; 55(4): 424-32.

15. Jonsson H, Borell L, Sadlo G. Retirement: An Occupational Transition with Consequences for Temporality, Balance and Meaning of Occupations. Journal of Occupational Science. 2000; 7(I): 29-37.

16. Pettican A, Prior S. 'It's a new way of life': an exploration of the occupational transition of retirement. British Journal of Occupational Therapy. 20I I; 74(I): I2-9.

17. Wiseman L, Whiteford G. Understanding occupational transitions: A study of older rural men's rural men's retirement experiences. Journal of Occupational Science. 2009; 16(2): 104-9.

18. Blair S. The Centrality of Occupation during Life Transitions. British Journal of Occupational Therapy. 2000; 63(5): 231-7.

19. Lessard A, Butler-Kisber L, Fortin L, Marcotte D, Potvin P, Royer E. Shades of disengagement: high school dropouts speak out. Sociology, Psychology Education. 2008; I I: 25-42.

20. Archambault I, Janosz M, Fallu J, Pagini L. Student engagement and its relationship with early school dropout. Journal of Adolescence. 2009;32:65I-70.

21. Instant Grass. Youth Policy Initiative. Instant Grass Presentation of Youth Voices. Round Table 4: Learner Retention. 2007.

22. Motala S, Dieltiens V, Sayed Y. Physical access to schooling in South Africa: mapping dropout, repetition and age-grade progression in two districts. Comparitive Education. 2009; 45(2): 25I-63.

23. Scanlon D, Mellard D. Academic and participation profiles of schoolage dropouts with and without disabilities. Exceptional Children. 2002; 68(2): 239-58.

24. Tidwell R. Dropouts Speak Out: Qualitatative Data on Early School Departures. Adolescence. 1988; 23: 939-54.

25. Mahoney J, Cairns R. Do Extracurricular activities protect against early school dropout? Developmental Psychology. 1997; 33(2): 24I53.

26. Ream R, Rumberger W. Student Engagement, Peer Social Capital, and School Dropout Among Mexican American and Non-Latino White Students. Sociology of Education. 2008; 8I: 109-39.

27. Heers M, Van Klaveren C, Groot W, van den Brink HM. Community Schools: What We Know and What We Need to Know. Review of Educational Research. 2016: I-36.

28. Halpern A. Quality of life as a conceptual framework for evaluating transition outcomes. Exceptional Children. 1993; 59: 486-98.

29. Rumberger R. Dropping out of middle school: A multilevel analysis of students and schools. American Educational Research Journal. 1995;32:583-625.

30. Bickel R, Papagiannis G. Post-high school prospects and district-level dropout rates. Youth and Society. $1988 ; 20(2)$ : 123-47.

31. Biddle B, Bank B, Anderson D, Keats J, Keats D. The Structure of Idleness: In-school and Dropout Adolescent activities in the United States and Australia. Sociology of Education. 1981; 54(2): 106-19.

32. Nesman T. A Participatory Study of School Dropout and Behavioural Health of Latino Adolescents. Journal of Behavioural Health Services \& Research. 2007; 34(4): 4I4-30.

33. Swaim RC, Beauvais F, Chavez E, Oetting E. The effect of school dropout rates on estimates of adolescent substance use among three racial/ethnic groups. American Journal of Public Health. 1997; $87(\mathrm{I}): 5 \mathrm{I}-5$.

34. Aloise-Young PA, Chavez E, 39(5), 539. Not all School Dropouts are the Same: Ethnic Differences in the Relation between Reason for Leaving School and Adolescent Substance use. Psychology in the Schools. 2002; n-based research. Australian Occupational Therapy Journal. 2003; 50: 86-91.

35. Aloise-Young PA, Chavez E, 39(5), 539. Not all School Dropouts are the same. Ethnic differences in the relation between research for 
leaving school and adolescent substance use. Psychology in Schools. 2002;39(5): 539-47.

36. Denzin NK. Interpretive Biography. Newbury Park: SAGE Publications, Inc, 1989.

37. Plummer K. Documents of Life 2. An invitation to a critical humanism. London: SAGE Publications Ltd, 200I.

38. Riessman CK. Narrative Analysis. Newbury Park, California: SAGE Publications, Inc; 1993.

39. Atkinson R. The Life Story Interview. Thousand Oaks, California: SAGE Publications, Inc; 1998.

40. Polkinghorne D. Narrative configuration in qualitative analysis. International Journal of Qualitative Studies in Education. 1995; 8(I): 5-23.

4I. Cresswell JW. Educational Research: Planning, conducting, and evaluating quantitative and qualitative research. Upper Saddle River, NJ: Pearson Education, 2002.

42. Miles M, Huberman A. Qualitative data analysis: an expanded sourcebook. 2nd ed. Thousand Oaks, California: Sage Publications, Inc., 1994.

43. Blumenfeld-Jones $D$. Fidelity as a criterion for practicing and evaluating narrative inquiry. In: Hatch A, Wisniewski R, editors. Life history and narrative. London: Falmer Press, 1995.

44. DePoy E, Gitlin L. Introduction to Research: Understanding and applying multiple strategies. United States of America: Mosby, Inc., 1998.

45. Watson R, Fourie M. International and African Influences on occupational therapy. In: Watson R, Swartz L, editors. Transformation through Occupation. London, England: Whurr Publishers, 2004.

\section{Corresponding Author}

Liesl Peters

liesl.peters@uct.ac.za 